\title{
The triangular relationship between public concern for environmental issues, policy output, and media attention
}

Zorzeta Bakaki, ${ }^{\mathrm{a}}$ Tobias Böhmelt, ${ }^{\mathrm{a}}$ and Hugh Ward ${ }^{\mathrm{a}}$

${ }^{a}$ Department of Government, University of Essex, UK

\begin{abstract}
Our work contributes to the literature as we theoretically argue for and empirically examine, for the first time, a triangular relationship between concern among citizens about the environment, media attention to environmental issues, and policy output. Previous work has studied these relationships, but analyzed the respective links rather in isolation from each other. This research has significant implications for the understanding of environmental policymaking and, more generally, informs the debate on whether politicians respond to what voters want and under what circumstances this occurs.
\end{abstract}

Keywords: Environmental policymaking; policy output; public opinion; media attention; triangular relationship 


\section{Introduction}

How does environmental policy output respond to citizens' concern and media coverage? Are public attitudes and media coverage assuaged when governments act? We theoretically argue for and empirically examine a triangular relationship between policy output, concern among citizens about the environment, and media coverage, in which each variable is influenced by the other two, creating an endogenous system.

Political outcomes in democratic systems tend to respond to changes in the public's leftright policy mood (Stimson et al. 1995). To varying degrees across domains, public spending is also shaped by relative policy preferences, because politicians may anticipate electoral advantage from accommodating citizen demand (Wlezien 1995, 2004). And even specific aspects of environmental policy are influenced by citizens' views (Johnson et al. 2005). Statistical work of the responsiveness of public policy is complemented by studies using ethnographic methods, which suggest that leaders attend to public concerns (Boswell et al. 2019). Hence, politicians, assumed to be office-seeking, take into account citizens' concerns about political issues, including the environment, which in turn affects how governments respond (Anderson et al. 2017). Alongside the public's influence on policy, mass media attract policymakers' attention and thus potentially shape policy outputs (e.g., Sevenans 2018), while media coverage can influence the public's views about political issues under some circumstances (Barnes and Hicks 2018, see also Elenbaas et al. 2013, Bakaki and Bernauer 2017a, Murphy and Devine 2019). We extend and widen the scope of research on public opinion, policy output, and media coverage, thereby making one central contribution.

Specifically, we examine how policy outputs, public opinion, and mass media coverage are related to and influence each other. We suggest that these three variables form a system in which each is related to the others. Earlier research provides some support for linkages between media, public opinion, and policy output. However, these contributions have focused on 
bivariate relationships and often assume that each relationship is unidirectional. We believe that specifying and examining a triangular system, jointly for the first time while recognizing reciprocal links and endogeneity, will shed new light on the persistent empirical ambiguity about how public opinion, media coverage, and environmental policy outputs are related to each other. Parts of this system can usefully be thought of as operating according to what Downs (1972) calls the 'issue-attention cycle,' whereby public concern - and, as we argue, media attention - is assuaged when politicians attend to the environment by developing policies. We claim that carefully modelling this system is crucial for furthering our understanding of what the public wants, whether politicians implement this in the environmental context, and which role media coverage plays.

\section{A triangular relationship}

The study of environmental policy output is strongly related to how states, and particularly democracies, perceive the need for ambitious environmental programs. Other research discusses how public opinion is related to environmental policymaking and outputs by examining people's preferences toward climate change and mitigation (e.g., Krosnick et al. 2006, Drews and Van den Bergh 2011). And there is an emerging debate about the role of mass media in shaping environmental politics (e.g., Meyer and Hinchman 2002, Gavin 2009). For the first time, we propose that these are not only bilateral relationships, but instead a triangular relationship is formed comprising reciprocal links between outputs, public opinion, and media coverage. Hence, theoretically and empirically, the effects of each variable on the others must be estimated as part of a system of simultaneous relationships.

The influences we ultimately expect are summarized in Figure 1: public opinion and media coverage are likely to be mutually reinforcing; public opinion should be positively related to policy outputs, but the latter is likely to exert a negative impact on public opinion; finally, 
media coverage is expected to be positively associated with policy outputs, but media attention may lower as soon as legislative action occurs. We argue for the need to examine the potential interdependencies between these factors. Because they form a system in which each is endogenous, failure to allow for reciprocal influences could lead to biased effect estimates. Interestingly, the recent literature has begun to recognize the importance of dealing with endogeneity in this context. Liu et al. (2011) argue for a simultaneous relationship between Congressional attention to and US media coverage of climate change in 1969-2005. They report that changes in the level of problem indicators, focusing events, and feedback from the scientific community affect attention, but they do not find cross effects from media coverage to Congressional attention. We follow Liu et al. (2011) in treating legislative action and media attention as endogenous, but we focus on legislative output, while allowing for endogeneity and considering additionally the effect of public opinion.

Figure 1. Triangular relationship of policy output, public opinion, and mass media

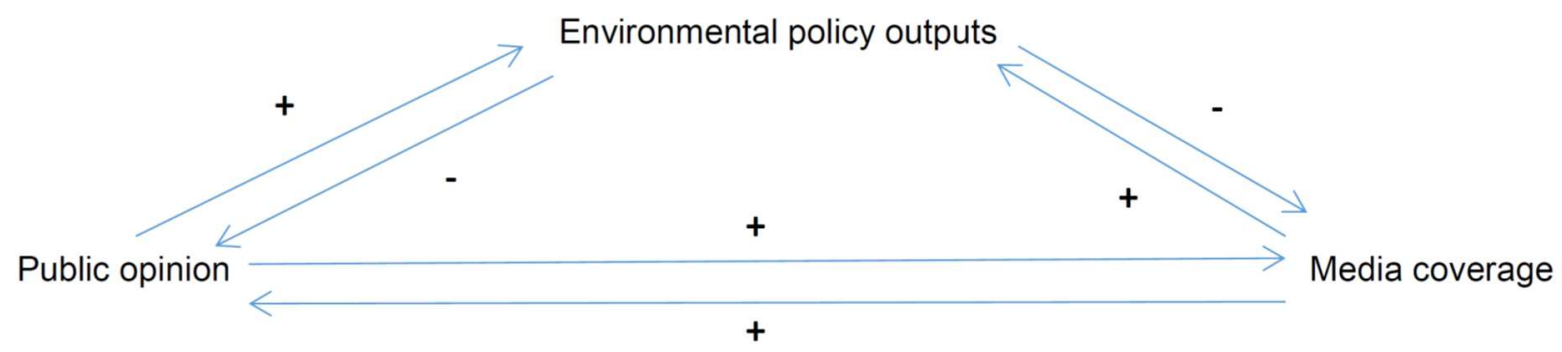

\section{Public opinion and policy output}

Environmental quality is frequently seen as a public good and, generally, democracies have a stronger commitment to providing public goods than non-democracies (Bättig and Bernauer 2009, Cao and Ward 2015, Böhmelt et al. 2016). In democracies, competition for office drives policy toward what the median voter wants (e.g., Soroka and Wlezien 2010). In comparison to authoritarian governments, democracies have larger winning coalitions, i.e., the group of individuals whose support is decisive for politicians to obtain or to retain office. Using private 
goods to gain support has higher costs relative to the provision of public goods when winning coalitions are large, though (Cao and Ward 2015), and democratic leaders not responding to public demands eventually lose support and can be more easily removed from office than autocrats (e.g., Böhmelt and Butkute 2018). Several authors suggest then that, in an effort to provide public goods, democracies are likely to commit to environmental policies (e.g., Bättig and Bernauer 2009, Schaffer and Bernauer 2014). There is, in fact, evidence that policymakers respond to increased public demand for pro-environmental policies (Agnone 2007, Anderson 2011, Weaver 2008, Vandeweerdt et al. 2016, Anderson et al. 2017). At the same time, lack of public concern impedes the low-carbon transition (Geels 2013).

Policy output is thus expected to respond to citizens' preferences, but punctuatedequilibrium theory suggests that changes in public opinion are the decisive factor (Jones and Baumgartner 2012, see also Baumgartner 2006). Typically, policy output is incremental, due to lack of attention by politicians and because special interests accrete around the status-quo to block change (Walgrave and Dejaeghere 2016). Only occasionally do issues advance into the macro-political realm where major policy shifts occur propelled by significant changes in public opinion. In sum, if there is sufficient support in democracies, policy outputs may respond to positive swings in public opinion (e.g., Agnone 2007, Anderson 2011, Weaver 2008, Vandeweerdt et al. 2016, Anderson et al. 2017). However, what is missing in this literature is an examination of how policy outputs affect public opinion. A reciprocal relationship seems plausible as, for example, demand for political action may decrease when policies have been put in place (Wlezien 1995, 2004).

According to Downs' issue-attention cycle (1972), ${ }^{1}$ policy output goes through phases in which public concern is assuaged once politicians address it with legislative action. Similar to

\footnotetext{
${ }^{1}$ Note, however, that Downs has been criticized for ignoring the way issue interlinkage can increase or suppress attention, for postulating too many cycle stages, and for neglecting the way that attention can be sustained when new institutional structures emerge (see Gupta and Jenkins-Smith 2015). It may also not account for the empirical pattern in relation to all aspects of public opinion about environmental issues (Holt and Barkemeyer 2012), though
} 
punctuated-equilibrium theory, underlying beliefs must be translated into the perception that the issue is sufficiently salient before policy outputs can occur. However, once the new regulatory regime is in place, citizens become aware of its costs, which sets off a downswing in issue salience or even public support (Downs 1972, p.40-41). Some citizens simply become uninterested in the issue (Downs 1972, p.41). ${ }^{2}$ On this basis, we expect a positive relationship between changes in public opinion and policy output, but a negative feedback loop from policy output to public opinion.

\section{Media attention and public opinion}

While much is already known about the individual-level correlates of environmental public concern (e.g., Bakaki and Bernauer 2017a,b, 2018), macro-level influences are less well understood. That said, among plausible determinants are different levels of media attention to environmental issues (Oehl et al. 2017). In general, the literature stresses the power of the media to set the public agenda (McCombs 2005, Dearing and Rogers 1996, Jones and Baumgartner 2012), while Iyengar and Kinder (2010) argue that mass media also affect the attention citizens pay to certain issues. In turn, topics that make it onto the public agenda shape public opinion (Joslyn and Haider-Markel 2001, Murphy and Devine 2019). Environmental politics and the demand for 'greener' policies are unlikely to be an exception here. Mass media might play an important role in creating public awareness of environmental issues (Slovic 2000, Oehl et al. 2017, Barnes and Hicks 2018). The amount of information on environmental issues, in particular climate change, available to the public has increased considerably over the

\footnotetext{
Downs (1972) suggested that cycles are more likely to occur in some conditions, e.g., including benefits of action being concentrated in a minority with costs widely spread.

${ }^{2}$ In contrast to the issue-attention cycle, the thermostatic model postulates that, where citizens' preferences vary, policy responds to the difference between the level of policy and the median citizen's preferred level (Wlezien 1995) or the public's average left-right policy mood (Stimson et al. 1995), resulting in negative feedback if policy overshoots the level citizens desire. Considering variation in public attitudes towards environmental policy across US states and across time, Johnson et al. (2005) find evidence for a thermostatic feedback effect reducing public concern when policy outputs are accompanied by actual improvement in water-pollution levels.
} 
recent past (e.g., Kahan et al. 2012). In this context, some propose that the media can raise public awareness about environmental issues even among the least interested (see Dolan et al. 2012).

However, media coverage of climate change is usually of relatively low intensity and mass media may have only a modest influence on citizens' views and attitudes concerning environmental issues (Elenbaas et al. 2013, Bakaki and Bernauer 2017a, Oehl et al. 2017), although coverage and impact can peak around 'big events' such as the UNFCCC's Conferences of the Parties (Schmidt et al. 2013, Barkemeyer et al. 2017). And indeed, Scruggs and Benegal (2012) argue that the economic downturn of 2008 provides a more plausible explanation than the influence of media coverage on public opinion in the US, and certainly not all media coverage of climate change is prone to lead to greater public support for more ambitious policies: climate skepticism has become an important phenomenon, much of it emanating from right-wing think tanks and appearing in the 'blogoshere' (see also Boykoff 2013, Elsasser and Dunlap 2013). However, our empirical focus is on newspaper coverage.

There are relatively few quantitative-comparative studies of climate skepticism in newspapers. Painter and Ashe (2012) analyze newspaper coverage in the US, UK, France, India, China, and Brazil in 2007-2008 (when the IPCC's 4 ${ }^{\text {th }}$ Report was published) and 200910 (when the 'Climategate' scandal about the possible suppression of negative voices among the climate-science community broke out). Overall, climate skepticism was a relatively minor signal, occurring in around $12 \%$ of the newspaper coverage of climate change. That said, there was variation across countries, skepticism being considerably more prominent in US newspapers (where it occurred in around $33 \%$ of coverage in 2009-10) and somewhat more in the UK (ca. 18\% of coverage in 2009-10). In the UK, skepticism was particularly prominent in the right-of center press (also see Boykoff and Mansfield 2008). Based on an extensive survey of single-country qualitative and quantitative studies, Arnold et al. (2016) report little evidence 
for climate change skepticism in German, Norwegian, or French newspapers, though. While we cannot rule out the possibility of significant skeptical newspaper coverage in all European countries in our sample, we expect much of the coverage to reflect the consensus among climate scientists.

Taking all these arguments together, we suggest a positive feedback loop between public opinion and media coverage. Media coverage focuses on the more salient issues and this should be driven by public demand. When media gatekeepers come to regard a heavily-covered issue as stale, competitive pressures on available column-inches and journalistic resources may make them turn to what appears as more newsworthy issues. However, while public opinion is trending upwards, the media is likely to respond positively with more coverage, which induces the feedback between public opinion and media coverage.

\section{Media attention and policy output}

The 'mediatization' of politics over the past few decades underlines that media coverage is a dynamic and potentially highly influential force impacting on policymaking (Meyer and Hinchman 2002, Jones and Baumgartner 2012, Gavin 2009). For instance, in 1986, the German news magazine 'Der Spiegel' picked up on a report about climate change from a group of German scientists and ran an article under the heading 'The Climate Catastrophe,' with an iconic front cover showing Cologne Cathedral partially submerged by floodwaters. The term climate catastrophe became a discursive frame for the debate in Germany over the next thirty years (Oreskes et al. 2018, p.161).

Early discussions of the relationship between mass media and policymaking centered on the idea that the media occupy a liaison role between citizens and governments (Siebert et al. 1956, Baum and Potter 2008). Later on, work on the media-policy link became primarily the domain of agenda-setting research (Dearing and Rogers 1996). Media coverage can drive the political 
agenda and, in turn, environmental policy outputs (e.g., Trenz 2004): politicians may believe that the public is influenced by the media and then act on this premise; hence, media coverage is seen as a reflection of what the citizenry demand (Herbst 2002, Perloff 2002, Kepplinger 2007, Sevenans 2018). Policymakers, therefore, have incentives to process information in news media (Yanovitzky 2002), with unresponsiveness to the agenda potentially compromising their position (Edwards and Wood 1999, Oehl et al. 2017, Sevenans 2018). On the other hand, legislators strategically use the media to promote policies. Favorable coverage may increase their ability to get their policies successfully adopted and implemented (Holt and Barkemeyer 2012). In this manner, they can win important political gains with key constituencies (Edwards and Wood 1999, Walgrave and Van Aelst 2006).

Eventually, media coverage should indirectly influence policy output via its effects on public opinion, and there exists plausibly a direct impact as well. This occurs through informational and framing channels. Policymakers react to media coverage due to the information it contains; furthermore, there is a media-channel effect due to specific information the media reports (see also Sevenans 2018). Hence, what is covered, and the way in which this is done, frames the way politicians think. At the same time, the media tend to report on issues that are salient, both because of the journalistic norm that significant public issues should be addressed and as levels of readership are important to revenue streams (Hilgartner and Bosk 1988, Gupta and Jenkins-Smith 2015). ${ }^{3}$ To illustrate this, consider the Fukushima-Daiichi nuclear accident, which sparked a significant media campaign against nuclear energy in Germany. At least partially, this may have led to the government's decision to push more strongly for a nuclear power phase-out. But after legislative action took place, public interest declined and the media adjusted their coverage. In this regard, media gatekeepers react in a

\footnotetext{
${ }^{3}$ Holt and Barkemeyer (2012) find that a series of issue-attention cycles characterize media coverage of climate change, but that media attention to sustainable development might best be characterized step jumps in coverage that do not return to previous low levels as implied by Downs (1972).
} 
similar manner to the way in which Downs (1972) postulates voters react once politicians have dealt with an issue. In addition, if policy outputs assuage public concern and falling public concern leads to reduced media coverage, there is an indirect negative feedback loop between policy outputs and media coverage. Hence, we expect a positive relationship between media coverage and policy output, ${ }^{4}$ but a negative influence from policy output to media attention.

\section{Research design}

We compiled data for six established European democracies between 1983 and 2012: the UK, Ireland, the Netherlands, France, Spain, and Germany. The country-year is our unit of analysis, while the sample-countries and the time period are predetermined by data availability. The selection of states and years is thus entirely driven by data-availability criteria. As a result, there is no theoretical selection criterion for our sample except for states being democracies: the claim we develop is unlikely to apply in non-democratic environments.

Because of reciprocal influences of our three simultaneous-equations system, we rely on three-stage least-squares (3SLS) models. This estimation procedure combines seeminglyunrelated regression (SUR) with two-stage least squares estimation (2SLS). That is, 3SLS is suitable in a system of equations that are endogenous, i.e., in each equation there are endogenous variables on both the left and right-hand sides of the equation. This is the 2SLS component. On the other hand, 3SLS directly takes into account that the error terms in each equation are correlated, which is the SUR element. The combination of these two components is the key strength of 3SLS, but the main challenge is finding instruments for the main variables. We, therefore, discuss the validity of our approach and assess the strengths of our

\footnotetext{
${ }^{4}$ That said, media attention may not lead to more ambitious environmental policy outputs (see Lloyd 2004, Davis 2002, Lewis et al. 2008a,b). For instance, the media could misinterpret information (Boykoff and Boykoff 2004), which then has little impact or influence on policymaking. Environmental issues may also not be high enough on the agenda to stimulate the sort of public concern that prompts concerted political action (Gavin 2009).
} 
instruments in the appendix. We treat as endogenous variables policy output, media attention to environmental issues, and concern among citizens about the environment, which are fed into 3SLS in the following three steps.

First, all exogenous variables in the system are used to create the instrumented values of the endogenous items. As we outline below, we identify one unique instrument per endogenous variable, while controlling for unit-level fixed effects and a temporal trend. Therefore, we use all of these items to generate the instrumented values of the endogenous items. Second, 3SLS estimates a cross-equation covariance matrix. Third, we calculate the simultaneous equations with the three endogenized variables via generalized least squares, employing the instrumented variables and the exogenous items (i.e., unique instruments, fixed effects, and the time trend) as well as the estimated covariance matrix. We include country fixed effects alongside the substantive predictors to capture any time-invariant forms of cross-section heterogeneity as well as a linear time trend to address temporal autocorrelation more generally in each of the three equations. Finally, we incorporate temporally lagged dependent variables, which control for within-state path dependencies.

\section{Variables and data sources - Environmental policy output stage}

The first endogenous (outcome) variable focuses on policy outputs that could improve environmental quality. One of the most significant environmental problems of our time is climate change, and it is strongly related to countries' energy policies (Schaffer and Bernauer 2014). Moreover, a key step to limiting the effects of climate change and transitioning to a lowcarbon society is the de-carbonization of the energy sector (OECD/IEA/NEA/ITF 2015). Accordingly, we employ a measure of states' renewable energy policies for the first endogenous item using data from the IRENA/IEA Global Renewable Energy Policies and Measures database. We concentrate on national policies and measures (henceforth, for brevity, 
policies) pertaining to one of the following categories: economic instruments, information and education, policy support, regulatory instruments, research and development, and voluntary approaches. The date each policy came into force and ended is provided by the IRENA/IEA database, and we used this information to code a variable counting the number of renewable energy policies a state has introduced in each year over our sample period. As Cao and Ward (2017, p.89f) emphasize, this variable 'is more closely related to climate change [than general measures of the stringency of environmental policy].' After accounting for missing values, we have 77 country-year observations with a mean value of 1.57 new policies introduced per year (standard deviation of 1.77).

To instrument policy outputs, we need a variable that is directly associated with this measure, but not the other endogenous items described below. Considering several theoretical claims and after a series of empirical checks, we identified a one-year lagged binary natural disaster variable as the instrument of our choice: governments tend to respond to natural disasters, though not always with appropriate policies that consider second-order effects (Neumayer et al. 2014). Moreover, there is evidence that policymakers react to environmental influences by implementing environmental policies after natural disasters (Bechtel and Hainmueller 2011). To this end, we use the EM-DAT International Disaster Database to code all climatological, geophysical, hydrological, and meteorological disasters per year. To minimize likely bias stemming from coding or measurement error, we transformed this information into a binary item that receives a value of 1 if at least one such disaster occurred in a given year (0 otherwise). Dichotomizing this item also helps meeting the instrumentalvariable requirements of the estimator, which, e.g., a count variable does not. The crucial advantage of this Disaster Onset dummy (mean value of 0.69; standard deviation of 0.47 ) is that, unlike factors such as carbon dioxide emissions, it is truly exogenous to any of the three outcome variables we have. 


\section{Variables and data sources - Environmental public opinion}

The second endogenous variable is based on the Eurobarometer survey. The EU Commission has conducted such surveys since the 1970s. Unfortunately, the Eurobarometer does not ask the same question(s) in every survey, most questions are not about renewable energy or climate change, and question formulations differ. With a view to capturing our theoretical concept as closely as possible while maximizing country-year coverage, we opted for a combination of two Eurobarometer survey items. First, there is the question on whether respondents thought that fighting pollution is (4) not at all important, (3) of little importance, (2) important, and (1) very important. The item has not been included in all Eurobarometer surveys and this question was replaced by another ordinally scaled question in some, and particularly in more recent, surveys: "please tell me, for the problem of protecting nature and fighting pollution, whether you personally consider it a very important problem (1), important (2), of little importance (3), or not at all important (4).' Both items should strongly correlate with the unobserved public view on climate change and renewable energy.

We combined these two survey questions as follows: we first dropped the 'don't know' answers and missing values. Afterwards, we merged both variables as they follow the same scale and inverted the result, so that higher values pertain to a more favorable attitude toward environmental quality. Third, we aggregated this individual-level information to the country level by averaging across respondents. We thus compiled a variable measuring the average public mood toward protecting nature and fighting pollution, which theoretically ranges in [1; 4] with higher values indicating that a larger share of respondents perceives environmental 
protection as important. Finally, we subtracted the variable's values in $t$ - 1 from current values. Our final item has a mean value of 0.065 and a standard deviation of $0.49 .^{5}$

To instrument public opinion, we used annual data on median voter preferences from the Eurobarometer's item that asks respondents to place themselves on a left-right scale from 1 (left) to 10 (right). We incorporated the lagged median-voter position in the empirical analysis and focused on inter-annual changes. Changes in the median voter are directly tied to public opinion shifts about the environment. For example, left wingers are significantly more likely to express environmental concern than right wingers (e.g., Kvaløy et al. 2012). However, a direct effect on environmental policy or media attention may not necessarily be present. The variable has a mean value of -0.005 and a standard deviation of 0.08 .

\section{Variables and data sources - Environmental media coverage}

The third endogenous variable pertains to media coverage of environmental issues. Schmidt et al. (2013) compiled data on newspaper coverage of climate change for 1996-2010. The authors have chosen lead print media for the six countries comprising our sample as these can maximize ‘circulation, reputation, or quality of journalism' (Schmidt et al. 2013, p.7). Out of these media outlets, Schmidt et al. (2013, p.7) identified all articles that referred to climate change directly or indirectly, i.e., a 'reference to climate change exists when: a) the keyword 'climate' appears in connection with words indicating change (i.e., change, development, warming, cooling); b) the article includes words synonymous with climate change, such as 'greenhouse effect' or 'global warming'; or c) when a global change of temperature is discussed.' Finally, 'the number

\footnotetext{
${ }^{5} \mathrm{We}$ assume that public concern over the environment positively correlates with public concern over climate change. We eventually opted for Eurobarometer data on environmental changes more generally due to the larger country-year coverage. In fact, there are only two Eurobarometer years that deal explicitly with climate change in our time period, one of them (1993) overlaps with the item on environmental concerns generally. Specifically, in Eurobarometer 39.1, the following question was included: 'Can you tell me if the greenhouse effect (global warming) is a very serious problem (1), quite serious (2), or not very serious (3)?' The pairwise correlation of this item with our non-inverted data on environmental concerns generally is $r=0.7140$ (with $p=0.0061$ ).
} 
of articles referring to climate change was then related to the absolute number in order to calculate coverage of climate change as a proportion of the absolute number of articles by month in percent' (Schmidt et al. 2013, p.8). As the original data only cover the period from 1996 to 2010, we linearly (following the temporal trend in the original observation period) extended the data beyond 2010 and before 1996. The final variable has a mean value of 0.589 (standard deviation of 0.623 ), indicating that climate change was on average covered by about 0.6 percent of all articles.

To instrument Media Coverage, we rely on lagged annual GDP growth from the World Bank Development Indicators, which define this variable as the 'annual percentage growth rate of GDP at market prices based on constant local currency. Aggregates are based on constant 2010 US Dollars. GDP is the sum of gross value added by all resident producers in the economy plus any product taxes and minus any subsidies not included in the value of the products.' If the media prioritize issues they see as important to readers or to what they conceive of as the national interest (Hilgartner and Bosk 1988), coverage of climate change should fall in periods of slow growth (Barkemeyer et al. 2017). The state of the economy may not directly be associated with either environmental policies or public opinion, though (Kachi et al. 2015; Bakaki and Bernauer 2018). ${ }^{6}$ This item has a mean value of 1.94 (standard deviation of 2.56).

\section{Empirical findings}

Table 1 summarizes the main results based on 3SLS. Columns 2-4 pertain to the different equations of the system: Column 2 has Policy Output as the dependent variable, Column 3 has Media Coverage as the outcome, while the dependent variable in Column 4 is Public Opinion Change. The parameter estimates can be interpreted directly, but to provide a more intuitive

\footnotetext{
${ }^{6}$ Counterarguments suggest, however, that more direct relationships exist. For example, regulations, often blamed for poor economic growth, could directly shape public opinion (see also Scruggs and Benegal 2012, Kahn and Kotchen 2011). We are aware of these claims and, thus, assess the validity of our instruments extensively in the appendix.
} 
interpretation of the main results, Figure 2 is a revised version of Figure 1 where only arrows that achieve statistically significant effects are retained. Finally, Figure 3 depicts the endogenous variables' marginal effects on the outcome variable at each stage.

Table 1. The triangular relationship between public concern for environmental issues, media coverage, and public policy output

\begin{tabular}{|c|c|c|c|}
\hline & Policy Output & Media Coverage & Public Opinion Change \\
\hline Lagged Dependent Variable & $\begin{array}{l}0.377 \\
(0.114) * * *\end{array}$ & $\begin{array}{l}0.867 \\
(0.097) * * *\end{array}$ & $\begin{array}{l}-0.794 \\
(0.079) * * *\end{array}$ \\
\hline Policy Outputt-1 & & $\begin{array}{c}0.045 \\
(0.030)\end{array}$ & $\begin{array}{l}0.011 \\
(0.027)\end{array}$ \\
\hline Public Opinion Change & $\begin{array}{c}0.741 \\
(0.404)^{*}\end{array}$ & $\begin{array}{l}0.289 \\
(0.107)^{* * *}\end{array}$ & \\
\hline Media Coverage $_{t-1}$ & $\begin{array}{c}0.465 \\
(0.355)\end{array}$ & & $\begin{array}{l}-0.369 \\
(0.085)^{* * *}\end{array}$ \\
\hline Disaster Onsett-1 & $\begin{array}{l}0.870 \\
(0.357)^{* *}\end{array}$ & & \\
\hline GDP Growth $_{\mathrm{t}-1}$ & & $\begin{array}{l}0.063 \\
(0.015)^{* * *}\end{array}$ & \\
\hline Median Voter Change & & & $\begin{array}{l}-0.849 \\
(0.436)^{*}\end{array}$ \\
\hline Temporal Trend & $\begin{array}{c}0.034 \\
(0.023)\end{array}$ & $\begin{array}{c}0.003 \\
(0.006)\end{array}$ & $\begin{array}{l}0.013 \\
(0.006) * *\end{array}$ \\
\hline Constant & $\begin{array}{l}-67.710 \\
(46.259) \\
\end{array}$ & $\begin{array}{l}-5.387 \\
(11.798) \\
\end{array}$ & $\begin{array}{l}-25.758 \\
(10.963) \\
\end{array}$ \\
\hline Obs. & 77 & 77 & 77 \\
\hline RMSE & 1.263 & 0.340 & 0.301 \\
\hline $\mathrm{P}>\chi^{2}$ & 0.000 & 0.000 & 0.000 \\
\hline Fixed Effects & Yes & Yes & Yes \\
\hline
\end{tabular}

Note: Table entries are coefficients; standard errors in parentheses; * significant at 10 percent; ${ }^{* \star}$ significant at 5 percent; ${ }^{* * *}$ significant at 1 percent (two-tailed). 
Figure 2. Triangular relationship of policy output, public opinion, and mass media

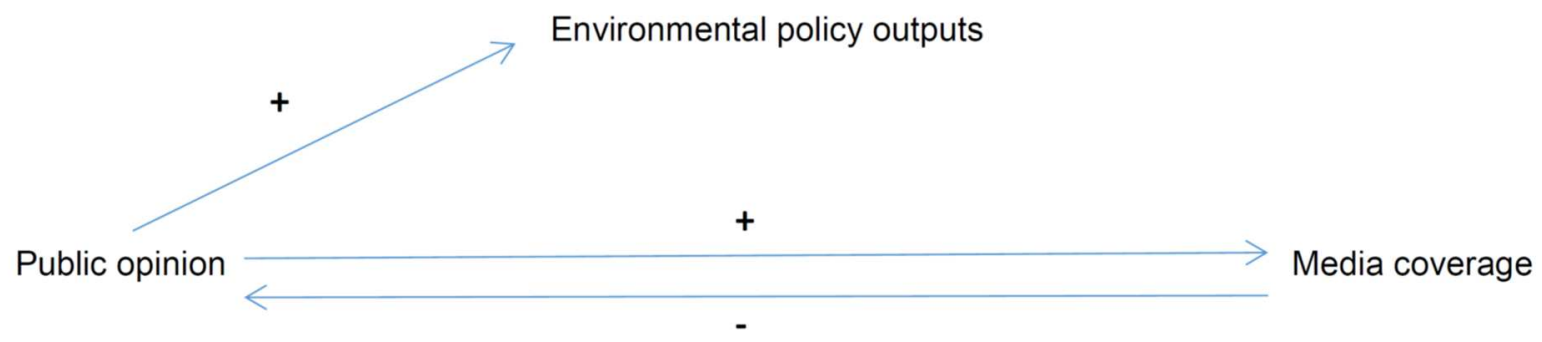

Figure 3. Marginal effects of endogenous variables

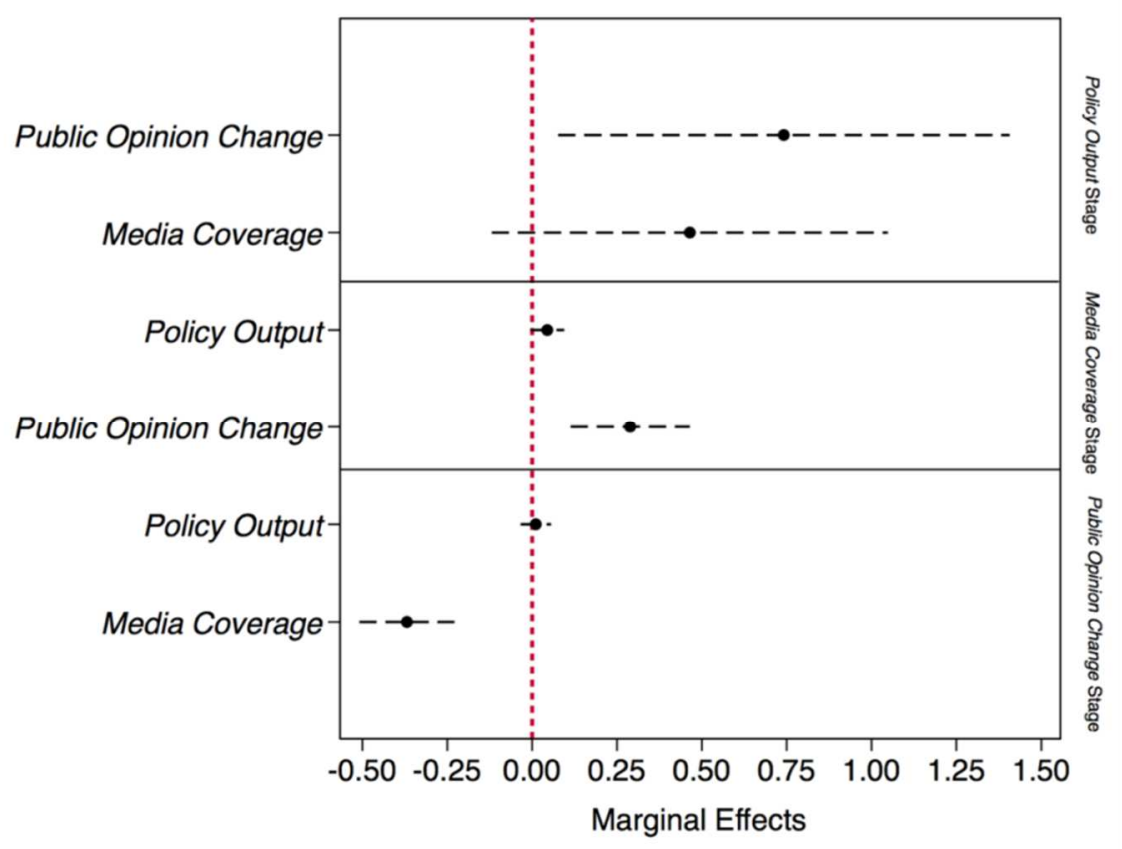

Note: Horizontal bars pertain to 90 percent confidence intervals; vertical bar pertains to marginal effect of 0 .

Table 1 shows that several of the endogenous items are strong predictors of each other. Specifically, Public Opinion Change positively correlates with renewable-energy policy outputs and it also influences Media Coverage positively. Interestingly, however, while Media Coverage does not seem to crucially influence policy outputs, it is a negatively-signed predictor of Public Opinion Change. Finally, Policy Output is unlikely to be a key driver of the public's attitude toward environmental quality or the media's coverage of it. As Figure 3 demonstrates, the magnitude of these effects is both substantively and statistically significant. When 
increasing Public Opinion Change by one unit, i.e. when the public has become more favorable of environmental protection over the last year, the predicted number of energy policies introduced in the current year increases by about 0.74 . At the same time, such a one-unit rise in Public Opinion Change leads to an increase of about 0.3 percent in the print-media coverage of climate change. And, finally, when paying attention to climate change in more articles by about 1 additional percentage point, the public will become less favorable towards environmental protection over the next year by about 0.37 units. The other links in Figure 3 are statistically insignificant (also Figure 2).

This suggests that influences may not be fully simultaneous in that an effect flows from any one factor to another and the other way around. First, Public Opinion Change affects policy outputs, but there is little evidence for an effect flowing the other way. The latter can be explained by opposing mechanisms: while we argued for a negative influence from policy output to public opinion, it may also be plausible to expect a positive association if legislative output creates a new constituency and, thereby, induces a positive feedback loop. For example, the legislature may mandate renewable portfolio standards, while this may lead to the establishment of a renewable industry, and the public may begin to recognize its importance even more. If both this and our postulated mechanism are at work, they could cancel each other out, leading to the overall insignificance we report above. Second, Public Opinion Change positively influences what media cover. Third, while we find support for Media Coverage influencing the public's attitudes toward the environment, the estimated effect is negative i.e., the more the media address environmental issues, the more uninterested citizens become in the issue. This seems unexpected, but it may be consistent with some mechanisms identified in the literature on the psychology of climate-change denial (Stoll-Kleemann et al. 2001): when extensive media coverage occurs, citizens who feel that there is little they can do about it may experience cognitive dissonance, leading to denial of the scientific consensus about climate 
change and/or of any individual responsibility; and, if widespread enough, these reactions could lead to loss of public support. Fourth, policy outputs neither influence media coverage nor public opinion. Finally, the 'positive' relationship between public opinion and policy outputs means that if the salience of environmental issues increases in the public's view, we observe more policy outputs. This also means, however, that lower salience put on the environment by the public induces less legislative action. And this is where the media come in - with a negative indirect effect: media coverage does not directly shape policy outputs, but indirectly via public opinion. Eventually, this leads to the chain of more media attention leading to less environmental salience in the public, which then induces less environmental policy action. Note, however, that media coverage is not significantly related to policy outputs directly and, hence, there is no contradiction in the results as such.

\section{Conclusion}

This article contributes to the literature by modeling a triangular system of reciprocal ties linking policy output, media attention, and public opinion about environmental quality. It is our belief that making this key advance over previous work could shed new light on how policymaking is related to public opinion, the media, and the other way around. Our findings, based on the analysis of six European democracies in 1983-2012, partially support this expectation: policy outputs are driven by public opinion when controlling for the persistent endogeneity, while public concern for the environment also shapes what the media covers. In turn, the latter affects whether citizens view environmental quality as a salient concern, although we found the effect to be negative. And while policy output is then driven, directly and indirectly, by public opinion and media coverage, it does not affect the others as a predictor.

An intriguing finding from our study is that media coverage negatively influences public opinion. It is possible that the public simply suffers from 'news fatigue' in relation to climate 
change coverage: the more the issue is covered, the more hopeless things look and the more pointless individual action may seem; cognitive dissonance sets, leading to the thought that the problem is not important. Our measure of media coverage purely concerns the amount, not the specific content, though. As noted above, climate-skeptical newspaper coverage does occur in Europe, and it is possible that more detailed content analysis would uncover links between it and public support.

By relying on and analyzing data from the Eurobarometer, we also add to the discussion about the value and limitations of survey-based research. The Eurobarometer is one of the most methodologically rigorous regional cross-national survey projects, having the key advantage of standardized survey practices across rounds. However, the Eurobarometer is not free of methodological criticism, and it may be problematic when trying to draw inferences about individual-level parameters: the macro-level correlation of a variable with an item that is strictly speaking measured at the individual level may lead to the wrong inferences. In addition, the Eurobarometer does not interview the same individuals over time, while it only captures a set of relatively high-developed, democratic states in which media and public opinion function relatively independently. This may also limit the generalizability of these data.

Future work should study more thoroughly the scope conditions of our triangular system. For instance, we claim that public interest in environmental policies declines once policies are in place. However, this may be linked to the effectiveness of the policies - public interest may not decrease if, e.g., policy outputs are ineffective in addressing an environmental problem (Johnson et al. 2005). We might also examine spillover effects, e.g., developments in policy abroad could influence 'home' policy making, media coverage, or public opinion. Moreover, more detailed content analysis able to distinguish between coverage along a spectrum from that liable to provoke public concern to denial at the other end is needed. Finally, it seems plausible that online newspapers spot public demand more easily and accurately than 'paper only' 
outlets, which we focus on. A crucial aspect for addressing those avenues for future research will be data availability and more comprehensive efforts: our setup comprises fewer than 100 observations - more data are clearly necessary, in particular for media coverage and attention.

From a policy perspective, our research highlights two crucial aspects. On one hand, we find evidence that policymakers react to what the public wants. Hence, the importance of the median voter in states' policymaking remains to be strong. It is, therefore, not the case, at least in our sample, that politicians ignore the demands of their electorate - this is good news for the validity of core democratic principles when subscribing to the claim that the wider public is the sovereign in democratic forms of government (Rasmussen et al. 2018). On the other hand, indirect influences and effects from other factors, most importantly the media, should not be neglected. While public opinion shapes policy output, the former is driven by and affects the media. For instance, environmental groups may make use of our research to more fully understand the given dynamics to shift public opinion as a means to catalyze the passage of renewable energy policy at the federal level (also Anderson et al. 2017). Correspondingly, for fully understanding how environmental policy is made and implemented, policymakers, public institutions, and analysts must take more strongly the complex set of influences surrounding all elements of policy output, media coverage, and public opinion into account.

\section{References}

Agnone J., 2007. Amplifying public opinion: The policy impact of the US environmental movement. Social Forces, 85(4), 1593-1620.

Anderson, S., 2011. Complex constituencies: Intense environmentalists and representation. Environmental Politics, 20(4), 547-565.

Anderson, B., Böhmelt, T., and Ward, H., 2017. Public opinion and environmental policy output: A cross-national analysis. Environmental Research Letters, 12(114011), 1-10. 
Arnold, A., et al., 2016. European perceptions of climate change (EPCC): Socio-political profiles to inform a cross-national survey in France, Germany, Norway, and the UK. Oxford: Climate Outreach.

Bättig, M. and Bernauer, T., 2009. National institutions and global public goods: Are democracies more cooperative in climate change policy? International Organization, 63(2), 281-308.

Bakaki, Z. and Bernauer, T., 2017a. Do global climate summits influence public awareness and policy preferences concerning climate change? Environmental Politics, 26(1), 1-26.

Bakaki, Z. and Bernauer, T., 2017b. Citizens show strong support for climate policy, but are they also willing to pay? Climatic Change, 145(1-2), 15-26.

Bakaki, Z. and Bernauer, T., 2018. Do economic conditions affect public support for environmental policy? Journal of Cleaner Production, 195(1), 66-78.

Barkemeyer, R., et al., 2017. Media coverage of climate change: An international comparison. Environment and Planning C, 35(6), 1029-1054.

Barnes, L. and Hicks, T., 2018. Making austerity popular: The media and mass attitudes toward fiscal policy. American Journal of Political Science, 62(2), 340-354.

Baum, M.A. and Potter, P.B., 2008. The relationships between mass media, public opinion, and foreign policy: Toward a theoretical synthesis. Annual Review of Political Science, 11(1), 39-65.

Baumgartner, F., 2006. Punctuated equilibrium theory and environmental policy. In: Punctuated equilibrium and the dynamics of US environmental policy, edited by R. Repetto. New Haven, CT: Yale University Press, 24-46.

Bechtel, M., and Hainmueller, J., 2011. How lasting is voter gratitude? An analysis of the short and long-term electoral returns to beneficial policy. American Journal of Political Science, 55(4), 852-868. 
Böhmelt, T., Böker, M., and Ward, H., 2016. Democratic inclusiveness, climate policy outputs, and climate policy outcomes. Democratization, 23(7), 1272-1291.

Böhmelt, T. and Butkutè, E., 2018. The self-selection of democracies into treaty design: Insights from international environmental agreements. International Environmental Agreements, 18(3), 351-367.

Boswell, J., et al., 2019. What can political ethnography tell us about anti-politics and democratic disaffection? European Journal of Political Research, 58(1), 56-71.

Boykoff, M., 2007. Flogging a dead norm? Newspaper coverage of anthropogenic climate change in the United States and United Kingdom from 2003 to 2006. Area, 39(4), 470-481.

Boykoff, M., 2013. Public enemy no. 1? Understanding media representations of outlier views on climate change. American Behavioral Scientist, 57(6), 796-817.

Boykoff, M. and Boykoff, J., 2004. Balance as bias: Global warming and the US prestige press. Global Environmental Change, 14(2), 125-136.

Boykoff, M. and Mansfield, M., 2008. 'Ye olde hot aire:' Reporting on human contributions to climate change in the UK tabloid press. Environmental Research Letters, 3(2), 024002.

Cao, X. and Ward, H., 2015. Winning coalition size, state capacity, and time horizons: An application of modified selectorate theory to environmental public goods provision. International Studies Quarterly, 59(2), 264-279.

Cao, X. and Ward, H., 2017. Transnational climate governance networks and domestic regulatory action. International Interactions, 43(1), 76-102.

Davis, A., 2002. Public relations democracy: public relations, politics and the mass media in Britain. Manchester: Manchester University Press.

Dearing, J.W. and Rogers E., 1996. Communication concepts 6: Agenda-setting. Thousand Oaks, CA: Sage. 
Dolan, P., et al., 2012. Influencing behavior: The mindspace way. Journal of Economic Psychology, 33(1), 264-277.

Downs, A., 1972. Up and down with ecology - The 'issue-attention cycle.' Public Interest, 28(2), 38-50.

Drews, S. and Van den Bergh, J., 2016. What explains public support for climate policies? A review of empirical and experimental studies. Climate Policy, 16(7), 855-876.

Edwards, G.C. and Wood, B.D., 1999. Who influences whom? The president, Congress, and the media. American Political Science Review, 93(2), 327-344.

Elsasser, S.W. and Dunlap, R.E., 2013. Leading voices in the denier choir: Conservative columnists' dismissal of global warming and denigration of climate science. American Behavioral Scientist, 57(6), 754-776.

Elenbaas, M., et al., 2013. The impact of media coverage and motivation on performancerelevant information. Political Communication, 30(1), 1-16.

Gavin, N., 2009. Addressing climate change: A media perspective. Environmental Politics, 18(5), 765-780.

Geels F., 2013. The impact of the financial-economic crisis on sustainability transitions: Financial investment, governance, and public discourse. Environmental Innovation and Societal Transitions, 6(1), 67-95.

Gupta, K. and Jenkins-Smith, H., 2015. Anthony Downs' 'Up and down with ecology: The issue-attention cycle.' In: The Oxford handbook of classics in public policy and administration, edited by Balla, S.J., Lodge, M., and Page, E. Oxford: Oxford University Press.

Herbst, S., 2002. How state-level policy managers 'read' public opinion. In: Navigating public opinion: Polls, policy and the future of American democracy, edited by Manza, J., Cook, F.L., and Page, B.I. Oxford: Oxford University Press. 
Holt, D. and Barkemeyer, R., 2012. Media coverage of sustainable development issuesattention cycles or punctuated equilibrium? Sustainable Development, 20(1), 1-17.

Hilgartner, S. and Bosk, C., 1988. The rise and fall of social problems: A public arenas model. American Journal of Sociology, 94(1), 53-78.

Iyengar, S. and Kinder, D.R., 2010. News that matters: Television and American opinion. Chicago, IL: University of Chicago Press.

Johnson, M., Brace, P., and Arceneaux, K., 2005. Public opinion and dynamic representation in the American states: The case of environmental attitudes. Social Science Quarterly, 86(1), 87-108.

Jones, B. and Baumgartner, F., 2012. From there to here: Punctuated equilibrium to the general punctuation thesis to a theory of government information processing. Policy Studies, 40(1), $1-19$.

Joslyn, M.R. and Haider-Markel, D.P., 2002. Framing effects on personal opinion and perception of public opinion: The cases of physician-assisted suicide and social security. Social Science Quarterly, 83(3), 690-706.

Kachi, A., Bernauer, T. and Gampfer, R., 2015. Climate policy in hard times: Are the pessimists right? Ecological Economics, 114(1), 227-241.

Kahan, D.M., et al., 2012. The polarizing impact of science literacy and numeracy on perceived climate change risks. Nature Climate Change, 2(10), 732-735.

Kahn, M.E., and Kotchen, M.J. 2011. Business cycle effects on concern about climate change: the chilling effect of recession. Climate Change Economics, 2(3), 257-273.

Kepplinger, H.M., 2007. Reciprocal effects: Toward a theory of mass media effects on decision makers. International Journal of Press/Politics, 12(3), 3-23. 
Krosnick, J.A., et al., 2006. The origins and consequences of democratic citizens' policy agendas: A study of popular concern about global warming. Climatic Change, 77(1-2), 743.

Kvaløy, B., Finseraas, H. and Listhaug, O., 2012. The publics' concern for global warming: A cross-national study of 47 countries. Journal of Peace Research, 49(1), 11-22.

Lewis, J., Williams, A., and Franklin, B., 2008a. A compromised fourth estate? UK news journalism, public relations, and news sources. Journalism Studies, 9(1), 1-20.

Lewis, J., Williams, A., and Franklin, B., 2008b. Four rumors and an explanation: A political economic account of journalists' changing newsgathering and reporting practices. Journalism Practice, 2(1), 27-45.

Liu, X., Lindquist, E., and Vedlitz, A., 2011. Explaining media and congressional attention to global climate change, 1969-2005: An empirical test of agenda-setting theory. Political Research Quarterly, 64(2), 405-419.

Lloyd, J., 2004. What the media are doing to our politics? London: Constable and Robinson.

McCombs, M., 2005. A look at agenda-setting: Past, present and future. Journalism Studies, 6(4), 543-557.

Meyer, T. and Hinchman, L., 2002. Media democracy: How the media colonize politics. Cambridge: Polity Press.

Murphy, J. and Devine, D. 2019. Does media coverage drive public support for UKIP or does public support for UKIP drive media coverage? British Journal of Political Science, Forthcoming.

Neumayer, E., Plümper, T. and Barthel, F., 2014. The political economy of natural disaster damage. Global Environmental Change, 24(1), 8-19.

Oehl, B., Schaffer, L., and Bernauer, T., 2017. How to measure public demand for policies when there is no appropriate survey data? Journal of Public Policy 37(2), 173-204. 
Oreskes, N., et al., 2018. The denial of global warming. In: The Palgrave handbook of climate history, edited by White, S., Pfister, C., and Mauelshagen, F. London: Palgrave.

Painter, J. and Ashe, T., 2012. Cross-national comparison of the presence of climate scepticism in the print media in six countries, 2007-10. Environmental Research Letters, 7(4), 044005.

Perloff, R.M., 2002. Third-person effect research 1983-1992: A review and synthesis. International Journal of Public Opinion Research, 5(2), 167-184.

Rasmussen, A., Reher, S., and Toshkov, D. 2018. The opinion-policy nexus in Europe and the role of political institutions. European Journal of Political Research: Forthcoming.

Schaffer, L. and Bernauer, T., 2014. Explaining government choices for promoting renewable energy. Energy Policy, 68(1), 15-27.

Schmidt, A., Ivanova, A., and Schäfer, M., 2013. Media attention for climate change around the world: A comparative analysis of newspaper coverage in 27 countries. Global Environmental Change, 23(5), 1233-1248.

Scruggs, L. and Benegal, S., 2012. Declining public concern about climate change: Can we blame the great recession? Global Environmental Change, 22(2), 505-515.

Sevenans, J., 2018. How mass media attract political elites' attention. European Journal of Political Science, 57(1), 153-170.

Siebert, F.S., Peterson, T. and Schramm, W., 1956. Four theories of the press. Chicago, IL: University of Illinois Press.

Slovic, P., 2000. The perception of risk. London: Routledge.

Soroka, S. and Wlezien, C., 2010. Degrees of democracy. Cambridge: Cambridge University Press.

Stimson, J., MacKuen, M., and Erikson, R., 1995. Dynamic representation. American Political Science Review, 89(3), 543-565. 
Stoll-Kleemann, S., O’Riordan, T., and Jaeger, C., 2001. The psychology of denial concerning climate mitigation measures: evidence from Swiss focus groups. Global Environmental Change, 11(2), 107-117.

Trenz, H., 2004. The democratizing dynamics of a European public sphere. European Journal of Social Theory, 7(1), 5-25.

Vandeweerdt, C., Kerremans B., and Cohn A., 2016. Climate voting in the US Congress: The power of public concern. Environmental Politics, 25(2), 268-288.

Walgrave, S. and Dejaeghere Y., 2016. Surviving information overload: How elite politicians select information. Governance, 30(2), 229-244.

Walgrave, S. and Van Aelst, P., 2006. The contingency of the mass media's political agenda setting power: Toward a preliminary theory. Journal of Communication, 56(1), 88-109.

Weaver A., 2008. Does protest behavior mediate the effects of public opinion on national environmental policies? A simple question and a complex answer. International Journal of Sociology, 38(3), 108-125.

Wlezien, C., 1995. The public as thermostat: Dynamics of preferences for spending. American Journal of Political Science, 39(4), 981-1000.

Wlezien, C., 2004. Patterns of representation: Dynamics of public preferences and policy. Journal of Politics, 66(1), 1-24.

Yanovitzky, I., 2002. Effects of news coverage on policy attention and actions: A closer look into the media-policy connection. Communication Research, 29(4), 422-451. 


\section{The triangular relationship between public concern for environmental issues, policy output, and media attention - Appendix}

\section{Assessing model specifications}

We also assessed whether the 3SLS estimation approach is valid and performed a series of tests. First, our instruments should be significant predictors for explaining the respective outcome variables they are directly connected to, but not the other endogenous factors. Table 1 in the main text demonstrates that the former applies, i.e., each instrument is statistically significant at conventional levels in its respective equation, while Table A.1 addresses the latter: we summarize the instruments' coefficient estimates and standard errors when regressing the other endogenous outcomes on them one at a time. As demonstrated in this table, none of the instruments is statistically significantly related to the other endogenous variables, i.e., an influence occurs only indirectly via the endogenous item they directly shape, which then affects the other outcomes.

Second, we test for the endogeneity of the three outcome variables. To this end, we first calculated the residuals for each stage (fully specified equations as in Table 1 of the main text) and then added these as a predictor to the other stages. Eventually, we end up with three regression estimations that are similar to the equations specified for our core model except that the residuals of equations 2 and 3 are added to equation 1, the residuals of equations 1 and 3 are added to equation 2, and the residuals of equations 1 and 3 are added to equation 3 . If the coefficient on the residuals is statistically different from 0 , the corresponding variable is indeed endogenous. Table A.2 summarizes the residuals' coefficients and standard errors at each stage: the residuals are mostly statistically significant, although the residuals are not statistically significant in the equation on Public Opinion Change. While conducting a 3SLS analysis seems still warranted, this test may provide some preliminary evidence that influence flows only in one direction for Public Opinion Change. 
Table A.1. Reduced-form regressions

\begin{tabular}{llll}
\hline & Policy Output & Media Coverage & Public Opinion Change \\
\hline Disaster Onsett-1 & & 0.153 & -0.183 \\
& & $(0.153)$ & $(0.119)$ \\
GDP Growtht-1 & -0.050 & & 0.021 \\
& $(0.079)$ & & $(0.022)$ \\
Median Voter Change & 1.503 & & 0.848 \\
& $(2.490)$ & & $(0.876)$ \\
\hline
\end{tabular}

Note: Table entries are coefficients; standard errors in parentheses.

Table A.2. Testing for endogeneity

\begin{tabular}{llll}
\hline & Policy Output & Media Coverage & Public Opinion Change \\
\hline Residuals Policy Output & & 0.095 & 0.028 \\
& & $(0.032)^{* * *}$ & $(0.032)$ \\
Residuals Media Coverage & 1.400 & & -0.124 \\
& $(0.468)^{* * *}$ & & $(0.123)$ \\
Residuals Public Opinion Change & 0.771 & -0.360 & \\
& $(0.697)$ & $(0.183)^{*}$ & \\
\hline
\end{tabular}

Note: Table entries are coefficients; standard errors in parentheses; ${ }^{*}$ significant at 10 percent; ${ }^{* *}$ significant at 5 percent; ${ }^{* * *}$ significant at 1 percent (two-tailed).

Finally, to test for over-identifying restrictions, we examine whether our instruments are correlated with the second-stage residuals. Hence, we estimated a regression using the residuals from Table 1 in the main text as the dependent variable and the instruments as the only explanatory variables. The instruments in this last test are all statistically insignificant, which is further supported by the F-test ( $F=0.100 ; p>F=0.9995)$. In sum, the specification of our 3SLS model seems generally adequate in that the instruments directly influence their respective outcomes, but not the other endogenous variables, as the three components of the triangular system mostly seem to be endogenous to each other, and since we cannot reject the null hypothesis of the test for over-identification and do not conclude that at least some of the IVs are not exogenous. Having said that, Public Opinion Change is somewhat of an outlier and, according to Table A.2, less endogenous to the other variables in the triangular system. 
Table A.3. The triangular relationship between public concern for environmental issues, media coverage, and public policy output, 1990-2012

\begin{tabular}{lcll}
\hline & Policy Output & Media Coverage & Public Opinion Change \\
\hline Lagged Dependent Variable & 0.377 & 0.892 & -0.835 \\
& $(0.130)^{* * *}$ & $(0.112)^{* * *}$ & $(0.108)^{* * *}$ \\
Policy Output -1 & & 5.187 & 0.009 \\
& & $(3.378)$ & $(0.030)$ \\
Public Opinion Change & 1.093 & 36.240 & \\
& $(0.522)^{* *}$ & $(13.605)^{* * *}$ & -0.004 \\
Media Coveraget-1 & 0.005 & & $(0.001)^{* * *}$ \\
& $(0.004)$ & & \\
Disaster Onset $t-1$ & 1.021 & & \\
& $(0.473)^{* *}$ & & \\
GDP Growth -1 & & 7.407 & -1.567 \\
& & $(1.768)^{* * *}$ & $(0.693)^{* *}$ \\
Median Voter Change & & & 0.029 \\
& & & $(0.011)^{* * *}$ \\
Temporal Trend & 0.038 & -1.100 & -57.292 \\
& $(0.045)$ & $(1.157)$ & $(22.275)^{* * *}$ \\
Constant & -76.071 & 2192.179 & 60 \\
& $(89.488)$ & $(2314.787)$ & 0.321 \\
Obs. & 60 & 60 & 0.000 \\
RMSE & 1.410 & 37.492 & Yes \\
P $>\chi^{2}$ & 0.000 & 0.000 & Yes \\
Fixed Effects & Yes & & \\
\hline
\end{tabular}

Note: Table entries are coefficients; standard errors in parentheses; * significant at 10 percent; ${ }^{* *}$ significant at 5 percent; ${ }^{* * *}$ significant at 1 percent (two-tailed).

\section{Examining different time periods}

The data setup in the main text is, as discussed, not without issues. Variable values for some country-years are linearly interpolated, some of our core variables are only available for a more limited time period, and the patterns we identify may apply to states and years outside the time period 1983-2012 as well. To this end, we examined two additional model specifications that are based on different periods of time and, thus, circumvent some of the issues associated with the main model's sample: first, we omit all country-years before 1990 and, second, all countryyears before 1996 are discarded from the analysis. These robustness checks take into account that the media-coverage data are interpolated before 1996 and that not that many renewable- 
energy policies were implemented before 1990. Tables A.3 (1990-2012) and A.4 (1996-2012) summarize our findings.

Table A.4. The triangular relationship between public concern for environmental issues, media coverage, and public policy output, 1996-2012

\begin{tabular}{|c|c|c|c|}
\hline & Policy Output & Media Coverage & Public Opinion Change \\
\hline Lagged Dependent Variable & $\begin{array}{l}0.391 \\
(0.137) * * *\end{array}$ & $\begin{array}{l}0.858 \\
(0.109) * * *\end{array}$ & $\begin{array}{l}-0.863 \\
(0.114) * * *\end{array}$ \\
\hline Policy Outputt-1 & & $\begin{array}{l}6.561 \\
(3.228)^{* *}\end{array}$ & $\begin{array}{c}0.015 \\
(0.031)\end{array}$ \\
\hline Public Opinion Change & $\begin{array}{l}1.026 \\
(0.542)^{*}\end{array}$ & $\begin{array}{l}35.099 \\
(12.747)^{* * * *}\end{array}$ & \\
\hline Media Coverage $_{t-1}$ & $\begin{array}{c}0.006 \\
(0.005)\end{array}$ & & $\begin{array}{l}-0.005 \\
(0.001) * * *\end{array}$ \\
\hline Disaster Onset $t_{-1}$ & $\begin{array}{l}1.140 \\
(0.544)^{* *}\end{array}$ & & \\
\hline GDP Growth $_{\mathrm{t}-1}$ & & $\begin{array}{l}5.565 \\
(1.735)^{* * *}\end{array}$ & \\
\hline Median Voter Change & & & $\begin{array}{l}-1.722 \\
(0.728)^{* *}\end{array}$ \\
\hline Temporal Trend & $\begin{array}{l}-0.023 \\
(0.085)\end{array}$ & $\begin{array}{l}-6.923 \\
(2.080)^{* * * *}\end{array}$ & $\begin{array}{c}0.017 \\
(0.020)\end{array}$ \\
\hline Constant & $\begin{array}{l}46.802 \\
(170.986)\end{array}$ & $\begin{array}{l}13890.91 \\
(4172.151)^{* * * *}\end{array}$ & $\begin{array}{l}-33.110 \\
(39.237)\end{array}$ \\
\hline Obs. & 54 & 54 & 54 \\
\hline RMSE & 1.473 & 35.646 & 0.332 \\
\hline $\mathrm{P}>\chi^{2}$ & 0.015 & 0.000 & 0.000 \\
\hline Fixed Effects & Yes & Yes & Yes \\
\hline
\end{tabular}

Note: Table entries are coefficients; standard errors in parentheses; * significant at 10 percent; ${ }^{* *}$ significant at 5 percent; ${ }^{* *}$ significant at 1 percent (two-tailed).

The substantive conclusions we discuss in the main text remain robust and there are virtually no differences in comparison to the main model. Essentially, the only key change pertains to the public-opinion variable in the media-coverage equation when looking at the 1996-2012 period: Public Opinion Change is now statistically significant, emphasizing that changes in the public mood also shape what the media covers. As expected, the relationship is positive, i.e., 
more environmental concern in people's views induces more media reporting about climate change.

\section{Alternative data for policy outputs}

The main text's analysis is based on policy-output data from the IRENA/IEA global renewable energy policies database. However, there are two problems associated with these particular data. First, these data may be too distant from actually addressing climate change as such, which is our theoretical focus when talking about environmental issues, media coverage, and even the public attitude. Second, except for Germany, not many countries implemented renewable-energy policies before the mid-1990s. As a result, we considered replacing the IRENA/IEA global renewable energy policies database by the database 'Addressing Climate Change. ${ }^{7}$ These data comprise all national policies that address climate change - not only renewable-energy aspects. The pairwise correlation of the two variables is, not surprisingly, quite high with $r=0.4160$. To meet the estimator's requirements for the instrument, i.e., to ensure that Disaster Onset is still a valid instrument for the new policy-output variable, we transformed missing values of the alternative indicator into 0 s, recoded it into a binary variable, and re-estimated the core model. The findings are presented in Table A.5.

This robustness check does not produce results that differ from those discussed in the main text. Even all instruments perform similarly in terms of direction of influence and statistical significance. What seems worth mentioning, though, is the positive and significant impact of Policy Output in the equation pertaining to Media Coverage: this relationship is now truly simultaneous in that policy outputs seem to increase media coverage, but also more media coverage leads to a higher likelihood of climate-change policies being introduced.

Table A.5. The triangular relationship between public concern for environmental issues, media coverage, and public policy output, alternative policy data

\footnotetext{
${ }^{7}$ Available online at: https://www.iea.org/policiesandmeasures/climatechange/.
} 


\begin{tabular}{|c|c|c|c|}
\hline & Policy Output & Media Coverage & Public Opinion Change \\
\hline Lagged Dependent Variable & $\begin{array}{l}0.352 \\
(0.127)^{* * *}\end{array}$ & $\begin{array}{l}0.873 \\
(0.093)^{* * *}\end{array}$ & $\begin{array}{l}-0.785 \\
(0.079) * * *\end{array}$ \\
\hline Policy Output ${ }_{t-1}$ & & $\begin{array}{l}28.788 \\
(15.551)^{*}\end{array}$ & $\begin{array}{c}0.001 \\
(0.142)\end{array}$ \\
\hline Public Opinion Change & $\begin{array}{c}0.143 \\
(0.087)^{*}\end{array}$ & $\begin{array}{l}22.826 \\
(10.549)^{* *}\end{array}$ & \\
\hline Media Coverage $_{t-1}$ & $\begin{array}{l}0.002 \\
(0.001) * * *\end{array}$ & & $\begin{array}{l}-0.004 \\
(0.001)^{* * *}\end{array}$ \\
\hline Disaster Onsett-1 & $\begin{array}{l}0.236 \\
(0.077)^{* *}\end{array}$ & & \\
\hline GDP Growth $_{\mathrm{t}-1}$ & & $\begin{array}{l}5.938 \\
(1.520) * * *\end{array}$ & \\
\hline Median Voter Change & & & $\begin{array}{l}-0.823 \\
(0.441)^{*}\end{array}$ \\
\hline Temporal Trend & $\begin{array}{c}0.012 \\
(0.007)^{*}\end{array}$ & $\begin{array}{l}-0.571 \\
(0.824)\end{array}$ & $\begin{array}{c}0.014 \\
(0.008)^{*}\end{array}$ \\
\hline Constant & $\begin{array}{l}-24.424 \\
(13.552)^{*}\end{array}$ & $\begin{array}{c}1116.798 \\
(1638.007)\end{array}$ & $\begin{array}{l}-26.938 \\
(15.732)^{*}\end{array}$ \\
\hline Obs. & 77 & 77 & 77 \\
\hline RMSE & 0.270 & 33.213 & 0.302 \\
\hline $\mathrm{P}>\chi^{2}$ & 0.000 & 0.000 & 0.000 \\
\hline Fixed Effects & Yes & Yes & Yes \\
\hline
\end{tabular}

Note: Table entries are coefficients; standard errors in parentheses; * significant at 10 percent; ${ }^{* *}$ significant at 5 percent; ${ }^{* *}$ significant at 1 percent (two-tailed).

\section{Changes in media coverage}

Punctuated-equilibrium theory suggests, as discussed in the main text, that changes in public opinion are the decisive factor. We do not have a similar argument or expectation for media coverage. That said, in the robustness check summarized in Table A.6, we look at the changes of media coverage rather than yearly levels.

Table A.6. The triangular relationship between public concern for environmental issues, media coverage, and public policy output, changes in media coverage 


\begin{tabular}{lcll}
\hline & Policy Output & Media Coverage & Public Opinion Change \\
\hline Lagged Dependent Variable & 0.347 & 0.069 & -0.692 \\
& $(0.111)^{* * *}$ & $(0.123)$ & $(0.086)^{* * *}$ \\
Policy Output ${ }_{\mathrm{t}-1}$ & & 2.638 & -0.013 \\
& & $(3.050)$ & $(0.030)$ \\
Public Opinion Change & 0.967 & 26.734 & \\
& $(0.420)^{* *}$ & $(11.700)^{* *}$ & -0.002 \\
Media Coverage $\mathrm{t}_{-1}$ & 0.010 & & $(0.001)^{*}$ \\
& $(0.004)^{* *}$ & & \\
Disaster Onset $t-1$ & 0.742 & & \\
& $(0.358)^{* *}$ & & \\
GDP Growth ${ }_{\mathrm{t}-1}$ & & 6.659 & -0.642 \\
& & $(1.639)^{* * *}$ & $(0.493)$ \\
Median Voter Change & & & -0.001 \\
& & & $(0.005)$ \\
Temporal Trend & 0.065 & -0.034 & 2.850 \\
& $(0.022)^{* * *}$ & $(0.566)$ & $(10.897)$ \\
Constant & -129.105 & 44.756 & 77 \\
& $(43.382)^{* * *}$ & $(1129.524)$ & 0.330 \\
Obs. & 77 & 77 & 0.000 \\
RMSE & 1.229 & 34.215 & Yes \\
P $>\chi^{2}$ & 0.000 & 0.001 & Yes \\
Fixed Effects & Yes & & \\
\hline
\end{tabular}

Note: Table entries are coefficients; standard errors in parentheses; * significant at 10 percent; ${ }^{* *}$ significant at 5 percent; ${ }^{* \star *}$ significant at 1 percent (two-tailed).

In some aspects, the results remain robust. In particular, this applies to the equation on policy outputs. However, the lagged dependent variable in the media-coverage equation has become statistically insignificant, while the estimates in the public-opinion equation of our model are mostly inconclusive, including the coefficient of the median-voter item. Ultimately, as we have little theoretical guidance to assume that changes in media coverage would matter, we have more confidence in the results based on the level of media coverage of climate change, which we discuss in the main text. 
Table A.7. The triangular relationship between public concern for environmental issues, media coverage, and public policy output, controlling for treaties of the European Union

\begin{tabular}{|c|c|c|c|}
\hline & Policy Output & Media Coverage & Public Opinion Change \\
\hline Lagged Dependent Variable & $\begin{array}{l}0.382 \\
(0.114) * * *\end{array}$ & $\begin{array}{l}0.847 \\
(0.086) * * *\end{array}$ & $\begin{array}{l}-0.822 \\
(0.081) * * *\end{array}$ \\
\hline Policy Outputt-1 & & $\begin{array}{l}5.425 \\
(2.665)^{* *}\end{array}$ & $\begin{array}{c}0.009 \\
(0.027)\end{array}$ \\
\hline Public Opinion Change & $\begin{array}{l}0.720 \\
(0.410)^{*}\end{array}$ & $\begin{array}{l}19.969 \\
(9.542)^{* *}\end{array}$ & \\
\hline Media Coverage $_{t-1}$ & $\begin{array}{c}0.004 \\
(0.004)\end{array}$ & & $\begin{array}{l}-0.004 \\
(0.001)^{* * *}\end{array}$ \\
\hline Disaster Onset $\mathrm{t}_{\mathrm{t}-1}$ & $\begin{array}{l}0.896 \\
(0.360) * *\end{array}$ & & \\
\hline GDP Growth $_{t-1}$ & & $\begin{array}{l}5.750 \\
(1.347) * * *\end{array}$ & \\
\hline Median Voter Change & & & $\begin{array}{l}-0.922 \\
(0.432)^{* *}\end{array}$ \\
\hline Temporal Trend & $\begin{array}{l}-0.017 \\
(0.063)\end{array}$ & $\begin{array}{l}-5.776 \\
(1.497) * * *\end{array}$ & $\begin{array}{c}0.009 \\
(0.015)\end{array}$ \\
\hline Maastricht Treaty & $\begin{array}{c}0.025 \\
(0.717)\end{array}$ & $\begin{array}{l}43.224 \\
(17.000)^{* * *}\end{array}$ & $\begin{array}{l}-0.219 \\
(0.174)\end{array}$ \\
\hline Amsterdam Treaty & $\begin{array}{l}1.065 \\
(1.047)\end{array}$ & $\begin{array}{l}90.318 \\
(24.690) * * *\end{array}$ & $\begin{array}{c}0.305 \\
(0.241)\end{array}$ \\
\hline Constant & $\begin{array}{c}33.375 \\
(125.446) \\
\end{array}$ & $\begin{array}{l}11454.730 \\
(2973.725)^{* * *}\end{array}$ & $\begin{array}{l}-17.241 \\
(29.984)\end{array}$ \\
\hline Obs. & 77 & 77 & 77 \\
\hline RMSE & 1.254 & 29.833 & 0.295 \\
\hline $\mathrm{P}>\chi^{2}$ & 0.000 & 0.001 & 0.000 \\
\hline Fixed Effects & Yes & Yes & Yes \\
\hline
\end{tabular}

Note: Table entries are coefficients; standard errors in parentheses; * significant at 10 percent; ${ }^{* *}$ significant at 5 percent; ${ }^{* \star *}$ significant at 1 percent (two-tailed).

\section{Controlling for treaties of the European Union}

Especially in the area of energy and environment, the European Union (EU) is a critical catalyzer of policy outputs. EU-commanded policies can also have significant effects on the other factors in the triangular relationship we argue for. For example, public environmental concern may increase in response to such stimulus from the EU. Or, in contrast, in EU-skeptic countries, EU-policy demands may be frowned upon by the public and decrease public support 
for environmental policies. As a robustness check, we thus ran our analysis while controlling for the adoption of the Maastricht Treaty and the Amsterdam Treaty, respectively. We created two binary variables to this end: one receiving values of 1 as of the year 1991 ( 0 otherwise) and a second item with values of 1 for the year 1997 and afterwards. The first variable then captures the influence of the Maastricht Treaty, while the second one controls for the effects stemming from the Treaty of Amsterdam.

According to Table A.7, our key findings are robust, but there are some interesting patterns for the two major EU agreements: while either treaty does not seem to crucially influence public opinion or policy outputs, we find strong and significant effects for the two variables in the media-coverage equation. In substantive terms, with the conclusion of the Maastricht Treaty and the Amsterdam Treaty, respectively, the coverage of climate change by mainstream media has significantly increased.

Table A.8. Disaggregation of environmental policy output

\begin{tabular}{ll}
\hline Economic instruments & Guarantee Scheme for Geothermal Energy, Netherlands 2009 \\
Information and education & Royal Decree Law 13/2012, Spain 2012 \\
Policy support & National Renewable Action Plan (NREAP), Ireland 2010 \\
Regulatory instruments & Renewable Energies Heat Act (EEWärmeG), Germany 2009 \\
Research and development & Research Councils Energy Programme (RCEP), UK 2004 \\
Voluntary approaches & Retailer Sustainable Commerce Agreement, France 2008 \\
\hline
\end{tabular}

\section{Overview of environmental policy output}

For the main analysis, we use the IRENA/IEA Global Renewable Energy Policies and Measures database. As discussed there, we concentrate on national policies and measures pertaining to one of the following categories: economic instruments, information and education, policy support, regulatory instruments, research and development, and voluntary approaches. In Table A.8, we provide examples for each of these categories that are part of our data sample. 